\title{
Decolonização do campo epistemológico da(s) Ciência(s) da(s) Religião(ões) e Teologia(s) pela via contra-hegemônica dos direitos humanos
}

\author{
Clarissa De Franco* \\ Nicolás Panotto**
}

\section{Resumo}

O texto traz um debate sobre o campo epistemológico das Ciência(s) da(s) Religião(ões) e Teologia(s), tendo como aporte teórico as teorias decoloniais e seus principais apontamentos críticos sobre as produções de conhecimento que desestabilizam a lógica moderna colonial e eurocentrada. O objetivo principal deste artigo é analisar os processos de colonialidade do saber constitutivo das áreas de estudos das religiões, considerando com maior ênfase a realidade dessas áreas no Brasil, e apresentar caminhos de desconstrução da lógica colonial nas práticas de pesquisa, ensino e extensão destes campos do conhecimento, pela via contra-hegemônica dos direitos humanos.

Palavras-chave: decolonialidade, epistemologia, Ciência(s) da(s) Religião(ões) e Teologia(s)

\section{Decolonization of the epistemological field of Science(s) of Religion(s) and Theology(ies) through the counter-hegemonic path of human rights}

\footnotetext{
Abstract

The text presents a debate on the epistemological field of Science(s) of Religion(s) and Theology(ies), having as theoretical support the decolonial theories and their main critical notes on the production of knowledge that destabilize the modern colonial and

* Professora titular do Programa de Pós-Graduação em Ciências da Religião da Universidade Metodista de São Paulo, psicóloga, doutora em Ciência da Religião, com pós-doutorado em Estudos de Gênero. E-mail: clarissa.franco@metodista.br .

** Doctor em Ciencias Sociales (FLACSO Argentina). Investigador associado del Instituto de Estudios Internacionales (INTE) de la Universidad Arturo Prat, Chile. E-mail: nicolaspanotto@gmail.com
} 
eurocentric logic. The main objective of this article is to analyze the coloniality processes of constitutive knowledge in the areas of studies of religions, considering with greater emphasis the reality of these areas in Brazil and to present ways of deconstructing the colonial logic in research, teaching and extension practices of these fields of knowledge, through the counter-hegemonic path of human rights.

Keywords: decoloniality, epistemology, Science(s) of Religion(s) and Theology(ies)

\section{Decolonización del campo epistemológico de la(s) ciencia(s) de la(s) religión(es) y la(s) teología(s) a través del camino contrahegemónico de los derechos humanos}

\section{Resumen}

El texto presenta un debate sobre el campo epistemológico de la(s) Ciencia(s) de la(s) Religión(es) y Teología(s), teniendo como soporte teórico las teorías decoloniales y sus principales apuntes críticos sobre la producción de conocimientos que desestabilizan la lógica colonial moderna y eurocéntrica. El objetivo principal de este artículo es analizar los procesos de colonialidad del conocimiento constitutivo en las áreas de estudio de las religiones, considerando con mayor énfasis la realidad de estas áreas en Brasil y presentar formas de deconstruir la lógica colonial en la investigación, la docencia y prácticas de extensión, de esos campos del conocimiento, a través del camino contrahegemónico de los derechos humanos.

Palabras-clave: decolonialidad, epistemología, Ciéncia(s) de la(s) religión(es) y Teología(s)

\section{Introdução}

A proposta deste artigo é analisar os processos de colonialidade do saber nas áreas de Ciência(s) da(s) Religião(ões) e Teologia(s) - as quais eventualmente chamaremos de CRT -, com foco na realidade do Brasil, bem como apresentar caminhos de desconstrução da lógica colonial nas práticas de pesquisa, ensino e extensão, desses campos do conhecimento, pela via contra-hegemônica dos direitos humanos.

O colonialismo e seus efeitos aprofundaram e produziram novas fraturas na construção das subjetividades e intersubjetividades, além de impactar de uma maneira estrutural a história do pensamento, reforçando prioridades científicas e epistemológicas que não refletem histórias locais, como padrões disciplinares, metodológicos e teóricos eurocêntricos.

Dividimos esse texto em três itens, além desta Introdução e das Considerações Finais. No primeiro item, trazemos uma discussão sobre os principais conceitos que envolvem a decolonialidade do saber, partindo 
de autoras/es de referência das teorias decoloniais, como Walter Mignolo, Catherine Walsh, Maldonado-Torres, Anibal Quijano, Boaventura de Sousa Santos, entre outros/as. Já o segundo momento do texto discute o processo de constituição das CRT, em especial considerando o contexto do Brasil, trazendo algumas tensões coloniais epistemológicas que cercam a área. Finalmente, apresentamos iniciativas que têm se consolidado como alternativas epistêmicas para os estudos das religiões dentro da perspectiva da decolonialidade.

\section{A decolonialidade do saber e o epistemicídio provocado pelo modelo eurocêntrico de produção de conhecimento}

Iniciamos esta reflexão defendendo o termo "decolonialidade". Entre o decolonial e o descolonial há mais que um "s". Catherine Walsh (2009) indica que a ideia da decolonialidade envolve um "caminho de luta contínua no qual podemos identificar, visibilizar e incentivar "lugares" de exterioridade e construções alternativas" (WALSH, 2009, p. 14-15), caminho esse que não está focado somente em reverter o colonial, mas em "provocar um posicionamento - uma postura e atitude contínua - de transgredir, intervir, insurgir e incidir" (WALSH, 2009, p. 14-15).

Este projeto radical de subversão do poder colonial leva à necessidade de decolonizar epistemologicamente os caminhos de conhecimento até então construídos, revisando de maneira visceral os campos do saber, a partir da compreensão de uma geopolítica mundial perversa e que nos leva a pensar que a desigualdade é algo banal ou "natural", ou que sempre tenha sido assim. Tal introjeção de lógicas modernas eurocentradas molda nossas relações, subjetividades e processos de produção de conhecimento. Como diz o sociólogo peruano Anibal Quijano (2000), a matriz colonialeurocêntrica-moderna que se construiu a partir dos "encontros coloniais" da história, ainda permeia nosso habitus pela presença de uma colonialidade do ser (que se traduz em hierarquias de racialização, classe e - acrescenta Lugones (2021) - de gênero), uma colonialidade do poder (que se inscreve nos tipos de instituições políticas e configurações sociais que herdamos para gerir o comum) e uma colonialidade do saber (que permeia diretamente no modo como em que a verdade impôs a legitimação racional e homogênea do conhecimento e da verdade).

Tais formas de colonialidade se manifestam de maneira articulada entre si, alimentando-se da lógica capitalista e racializada produzida e reforçada ao 
longo da extensa história colonial, que permanece após a colonização. Como "lado obscuro da modernidade" (MIGNOLO, 2006a, p. 16), a colonialidade estabelece modos de ser e de pensar, assim como modos específicos de produzir conhecimento e ciência.

Walter Mignolo (2008), junto com autoras e autores decoloniais (WALSH, 2009; CURIEL, 2007; 2008) propõem uma "desobediência epistêmica", um exercício de "aprender a desaprender, e aprender a reaprender” (MIGNOLO, 2008, p. 305).

A decolonialidade objetiva formar um pensamento que privilegie histórias locais e construa narrativas a partir de referências autóctones, resgatando histórias ocultadas, linguagens e conhecimentos subalternizados pelas narrativas coloniais que se tornaram hegemônicas. O processo de decolonialidade do saber envolve uma emancipação relativa aos sistemas de dominação referentes à colonialidade do poder, que envolve instâncias que controlam a economia, a autoridade, o gênero e a sexualidade, a subjetividade, o conhecimento e também a natureza e os recursos naturais (QUIJANO, 2005; MIGNOLO, 2010).

Critérios europeus de produção científica apoiaram-se na concepção de modernidade identificada com racionalidade, iluminismo e desenvolvimento humano que rejeita formas de construir conhecimento a partir de referências locais como saberes nativos. As críticas epistemológicas feministas apontaram desde a década de 1970 que princípios científicos como neutralidade, universalidade, objetividade, distanciamento entre sujeito e objeto, têm sido utilizados como manutenção de um ethos epistêmico patriarcal, elitista e branco, esvaziando a corporificação das verdades, as subjetividades, as histórias produzidas na coletividade, os saberes locais, a oralidade, as emoções e intuições como formas legítimas de produção de conhecimento (HARDING, 1998; HARAWAY, 1995).

Anibal Quijano lembra que o conhecimento produto da relação sujeitoobjeto "nega a intersubjetividade e a totalidade como sedes de produção de todo conhecimento" (QUIJANO, 2016, p. 64). Em especial, a premissa da universalidade tem chamado atenção dos estudos decoloniais, já que invisibiliza histórias locais e tende a homogeneizar experiências a partir de critérios externos. A descontrução deste tipo de lógica de produção de conhecimento é também uma construção e fortalecimento de caminhos até então invisibilizados, como forma de legitimar as ideias de universalidade e objetividade como elementos naturais da episteme colonial hegemônica, 
que intervém não apenas no conteúdo em si, mas também nos métodos e modos de construção.

No entanto, há um aspecto fundamental que os estudos sobre a decolonialidade -trouxeram à tona: não podemos falar de modernidade sem nos referirmos ao colonialismo. Enrique Dussel argumenta que "a expressão ontológica cartesiana (ego cogito) do século XVII foi antecipada pelo ego conquiro, ou ainda mais politicamente pelo ego domino ao Outro, o índio" (DUSSEL, 2009, p. 22). É por isso que a ideia europeia de modernidade conseguiu se universalizar e se impor como senso comum. Atingiu seu status excepcional graças ao empreendimento colonial que permitiu sua implantação coercitiva. Como enfatiza Edward Said (2002) sobre a conexão entre a construção do ocidental em relação às formas de definir o orientalismo, da mesma forma que a América serviu como aquele Outro, como espelho, para legitimar a autocompreensão europeia, a partir da lógica moderna (TODOROV, 2003). A América Latina é, então, uma "invenção" que ofereceu o estabelecimento da modernidade como projeto de poder, ao instituir contrastes simbólicos e imaginários entre o moderno e o primitivo, a pele branca e a pele negra, o avançado e o arcaico, a ciência e a superstição, a superioridade e a selvageria (MIGNOLO, 2005).

O colonialismo cumpre várias funções em relação à modernidade. Por um lado, estabelece uma matriz geopolítica que determina mecanismos de exploração (humana e ecológica) para viabilizar o estabelecimento do mercado capitalista e a industrialização. Recordemos também que os processos de "decolonização" e independência no século XIX foram acompanhados pela propagação de ideias nacionalistas e correntes de pensamento emancipatório que nasceram com os Estados-nação europeus. Mas para além dessas lógicas coloniais diretas, estabeleceu-se também um conjunto de demarcações que não se prendem necessariamente com um tipo de incidência direta, mas com a construção de um quadro de visão de mundo que, embora não atue de forma coerciva, estabelece-se de forma "indireta", através de processos de subjetivação e relações.

Mignolo (2004) afirma que o binômio modernidade/colonialidade constituiu-se por um período de autoafirmação dos "sucessos científicos", orientado para um progresso civilizatório pautado na racionalidade. Outro ponto que estrutura esta associação da colonialidade e modernidade é "uma história de negações e repúdios de todas as outras formas de racionalidade" (MIGNOLO, 2004, p. 680). A “modernidade (ciência, democracia, civilização, 
liberdade, capitalismo, etc.)" articulada com a "colonialidade (mito, folclore, despotismo, ignorância, pré-capitalismo, subdesenvolvimento, etc.)" define as "culturas do saber para as próximas décadas" (MIGNOLO, 2004, p. 704).

Boaventura de Sousa Santos (1999) propõe o termo "epistemicídio" para indicar o apagamento, destruição, inferiorização de saberes locais, desperdiçando possibilidades presentes na diversidade cultural. Já MaldonadoTorres (2004) aponta o silêncio decorrente do "racismo epistêmico" e CastroGomez (2005) fala de negação da alteridade epistêmica.

Aqui está um dos aspectos centrais da crítica decolonial da diversificação epistêmica: promover essa diversidade epistêmica não responde a uma descrição abstrata das singularidades, mas tem uma dimensão política intrínseca que confronta a homogeneidade colonial com a diferença colonial. É o que Arturo Escobar (2001) chama de política do lugar como forma de conferir uma dimensão política à diferença cultural que se inscreve na diversidade identitária, que não é apenas uma forma única de abordar o cosmológico ou natural, mas o reconhecimento de mundos-outros que habitam nosso planeta.

As compreensões da cultura local e do lugar se opõem ao espaço homogêneo circunscrito pela modernidade, o Ocidente e o próprio capital, especialmente no sentido da globalização. "O foco, portanto, se desloca para os múltiplos vínculos de identidade, lugar e poder - entre a criação de lugar e a criação de pessoas - sem naturalizar ou construir lugares como fontes de identidades autênticas e essencializadas" (ESCOBAR, 2001, p. 115). Aqui está uma crítica às mesmas ciências sociais e humanas nesses campos: silenciar esses esforços por trás da abstração de conceitos como capital, globalização ou Estado, faz perder de vista a presença de alteridades e movimentos subalternos que estão presentes em nossas vidas e contextos.

Esses termos representam as fraturas que o sistema colonial promove. A partir da metáfora do pensamento abissal, Boaventura de Sousa Santos (2007) defende que o pensamento moderno é pautado em uma divisão em duas realidades cognitiva e ontologicamente distintas, fissuradas, como se houvesse um abismo entre as mesmas, que não permite que as partes acessem a experiência da outra. Essas linhas visíveis e invisíveis que separam as realidades do pensamento moderno são pautadas em binarismos e dicotomias, como homem/mulher, preto/branco, Norte/Sul, centro/periferia, rico/ pobre, que em geral estabelecem lados, em que um grupo está marginalizado, silenciado e oprimido, enquanto o outro lado da fronteira mantém seu poder imperial e neocolonial. 
A violência e a desigualdade são elementos necessários para a manutenção do pensamento abissal, que é caracterizado pela impossibilidade de reconhecimento, compreensão, co-presença e diálogo entre os dois lados da linha. Em última instância, trata-se de uma negação absoluta do estatuto epistemológico de saberes não hegemônicos.

No âmbito científico, o pensamento abissal estabelece fronteiras entre categorias como o verdadeiro e o falso, o ilegal e o legal, o racional e o supersticioso, o objetivo e o vago, o neutro e o "contaminado".

O caminho de superação do pensamento abissal é pensar a partir do outro lado da fronteira, confrontando as tendências ao monoculturalismo europeu ou do Norte global, criando formas de uma contra-epistemologia ou epistemologias contra-hegemônicas, a que Boaventura de Sousa Santos chama de epistemologias do Sul (SANTOS, 2009). O pensamento pós-abissal desconstrói as dicotomias e desvitaliza as hegemonias, permitindo que a pluralidade epistêmica floresça.

Nesse sentido, a justiça colonial envolve a possibilidade das diferenças co-existirem e terem espaço de reconhecimento, em que "as práticas e agentes de ambos os lados da linha são contemporâneos em termos igualitários" (SANTOS, 2009, p. 45). Ao propor a ecologia do conhecimento ou a ecologia dos saberes (SANTOS, 2003; 2014), alerta para a necessidade de reconhecimento das contradições, ambiguidades e assimetrias presentes nos processos de diálogo das diferenças e interculturalidades, além de reforçar a possibilidade e também a urgência de uma articulação crítica entre saberes vindos das lutas sociais, saberes nativos e saberes de campos que gozam de maior oficialidade, como o campo científico, de forma a construir autonarrativas de povos subalternizados do Sul global sobre suas próprias experiências, com referenciais contra-hegemônicos, que confrontam as centralidades do saber e do poder.

A interculturalidade permite a compreensão da cultura e das relações culturais como constitutivamente conflitivas e tensas, reconhecendo espaço para as diferenças e abrindo caminhos para uma negociação cultural a partir do enfrentamento dos conflitos provocados pela assimetria do poder. Nesse caminho de novos horizontes epistemológicos, propomos reflexões para os campos das Ciência(s) da(s) Religião(ões) e Teologia(s). 


\section{Ciência(s) da(s) Religião(ões) e Teologia(s): reflexões sobre caminhos epistemológicos e práticas científicas}

As primeiras cátedras de Ciência(s) da(s) religião(ões) no mundo se estabeleceram na segunda metade do século XIX no campo da História das religiões (USARSKI, 2013). As Ciências da Religião nasceram, portanto, como campo disciplinar consolidado, em um período histórico em que a racionalidade científica apresentava tendências características de um cientificismo "arrogante" que tendia a rechaçar as religiões e o pensamento teológico como caminhos legítimos de produção de conhecimento, associado ao que Ahmet Kuru chama de "secularismo agressivo" (KURU, 2009), parte de uma cosmovisão eurocêntrica de mundo. Nesse sentido, para firmar-se como ciência, as Ciências da Religião eventualmente precisaram ao longo de sua "breve" história se "descolar" das Teologias como forma de busca por legitimidade acadêmica, já que o campo teológico é necessariamente vinculado ao religioso.

Nesse processo, o esforço de fortalecimento e legitimidade da área das CR levou a posições teóricas ambíguas em relação às Teologias, das quais ora se aproximava, e ora se distanciava. No Brasil, tais processos acabaram por culminar em uma área unificada na CAPES: Ciências da Religião e Teologia, após intensos e longos debates sobre as identidades de cada uma das áreas.

Esse processo está ancorado na perspectiva que Enrique Dussel (2005; 2016) aponta criticamente sobre a modernidade vista como uma emancipação da humanidade pela via do esforço da razão. Fenômenos como a Revolução Francesa, o Movimento Iluminista e a Reforma Protestante se tornaram marcos desta forma de aparente libertação e desenvolvimento, que se contrapõe às tradições medievais e católicas. Nesse sentido, a Europa se tornou o epicentro geopolítico dessa construção da ideia de modernidade.

No Brasil, as CRT compõem a área 44 na CAPES (Coordenação de Aperfeiçoamento de Pessoal de Nível Superior), vinculada ao Ministério da Educação, estando nesse momento sob a coordenação do docente Flávio Augusto Senra Ribeiro (coordenador da área), da docente Dilaine Soares Sampaio (coordenadora adjunta de Programas Acadêmicos) e do docente Claudio de Oliveira Ribeiro (coordenador de Programas Profissionais).

A área esteve, por muitos anos, subordinada à Filosofia, sendo a Teologia uma subcomissão da grande área Filosofia/Teologia. Em 2016, a portaria 174 criou as áreas de Filosofia e de Teologia separadamente, sendo essa última renomeada, posteriormente, como Ciências da Religião e Teologia. 
Essa breve história mostra como o caminho de constituição da área foi até muito recentemente subalterno, emprestando inicialmente sua legitimidade de áreas como a História e a Filosofia - essa última uma área com reconhecido prestígio internacional na academia, embora também nas fronteiras entre o científico e o não científico.

Embora tenha nascido da divisão disciplinar que ocorreu na concepção moderna de ciência, a(s) Ciência(s) da(s) Religião(ões) ocupa(m) um lugar ambíguo em relação à ciência, necessitando frequentemente sustentar os princípios da laicidade de Estado e da liberdade religiosa como balizadores de sua prática, como justificativa de se distanciar do rótulo "religioso". O documento da Área 44 na CAPES assim se pronuncia:

A área assegura em todos os seus procedimentos os princípios da laicidade do Estado, da liberdade religiosa de crença e de não crença e o rigor acadêmico na pesquisa sobre o objeto próprio que lhe compete investigar. Dessa forma, não se confunde com abordagens de caráter não científico ou pseudocientífico para o estudo das religiões e da Teologia. Tampouco reconhece, entre os seus programas, abordagens de corte sectarista, proselitista e fundamentalista, sendo estes critérios, entre outros, claramente definidos tanto no documento Critérios para Apresentação de Cursos Novos (APCN), quanto no presente Documento de Área. (SENRA; SAMPAIO; RIBEIRO, 2019, p. 06).

Já a Teologia, como termo, remete à Grecia Antiga e foi incorporada pelo cristianismo durante a Idade Média, estendendo-se na contemporaneidade ao estudo crítico também de outras tradições religiosas que não somente as cristãs.

Apesar de ser um campo de estudo antigo, ligado a figuras respeitadas do campo filosófico mundial, a Teologia no Brasil só teve seu reconhecimento oficial como área acadêmica pelo Ministério da Educação na década de 1990, quando se descolou dos seminários religiosos e passou a figurar oficialmente dentro das Universidades. Essa trajetória, que pode ser caracterizada em certo como ambígua e marginal dentro do campo científico, não goza de pleno reconhecimento público, uma vez que o sentimento ligado ao que apontamos como secularismo agressivo (KURU, 2009), que quer expulsar as religiões da esfera pública, junto com processos recentes que intensificaram o conservadorismo cristão na América Latina, culminando na defesa de pautas morais por religiosos/as no poder político, afeta diretamente a credibilidade das áreas que estudam as religiões, como Ciência(s) da(s) religião(ões) e Teologia. 
Quando essas áreas se posicionam publicamente de maneira crítica em relação aos fundamentalismos religiosos e às posturas religiosas antidemocráticas, colocando o ferramental da ciência para elaborar argumentos que sustentem sua posição, promovem animosidade em relação a esses grupos religiosos. E do ponto de vista interno às ciências, em relação aos demais campos científicos, as CR e Teologia produzem um esforço contínuo em se provar laicas, como já observado. Portanto, dentro e fora do contexto científico, o campo de estudos das religiões tem enfrentado desafios importantes, sob olhares desconfiados de seu status ambíguo e fronteiriço entre religião e ciência, entre tradição e modernidade.

Nesse contexto, uma abordagem decolonial permite identificar dois elementos. Primeiro, que a mesma teoria decolonial, de alguma forma, ainda continua a mostrar um certo reducionismo moderno e secularista ao não dar às religiões e espiritualidades o lugar epistêmico que merecem. Nesse sentido, como apresenta Javier Aguirre (2021), as abordagens pós/decoloniais ainda têm um longo caminho a percorrer nesse campo para chegar a uma crítica decolonial mais radical (Cf. YOUNTAE e CRAIG, 2021). Estudos religiosos e teológicos dentro da perspectiva pós/decolonial implicam dar conta dessa episteme-outra que serve para criticar a fundação religiosa/cristã que molda a modernidade e suas lógicas coloniais.

Nessa direção, Enrique Dussel, no texto: "Descolonização epistemológica da teologia" (DUSSEL, 2013), aponta a necessidade de reabilitar o messianismo originário cristão, indicando que o cristianismo se distanciou de sua origem em dois momentos da história, sendo o primeiro quando o cristianismo se funde com o Império romano, iniciando a era da cristandade. Dussel descreve esse período como: "inversão do messianismo para o cristianismo triunfante" (DUSSEL, 2013, p. 20) e alega que nesse momento, cristãos "deixam de ser críticos do império para serem seus decididos partidários, seus membros, e com o tempo seus defensores" (DUSSEL, 2013, p. 20-21). Já como segundo marco do distanciamento do cristianismo de sua missão originária, Dussel aponta o nascimento da modernidade (1492) e o projeto expansionista do cristianismo europeu em missão monocultural nas Américas. A cristandade imperial que “crucifica indígenas" (DUSSEL, 2013, p.23), também participa e legitima o processo de desumanização de grupos escravizados, sob a justificativa de não terem alma. Assumir essa participação nefasta do cristianismo na história da colonialidade e criar lugares de enunciação teológicos se faz necessário para uma decolonização profunda da Teologia. 
Nicolás Panotto (2019), considerando o contexto da Teologia cristã na América Latina, observa que a Teologia se vê em um contexto de diversas crises - "de identidade; cultural e contextual; espiritual, teológica e pastoral; epistemológica, pedagógica e didática; institucional e econômica; e crise de legitimidade" (PANOTTO, 2019, p. 86-89) - diante de tensões que emergem da pluralidade de crenças no contexto contemporâneo e das demandas da esfera pública laica com problemas complexos como bioética, diversidade de gênero, reivindicações de grupos minoritários, entre outras.

É diante desses importantes desafios que propomos reformulações para a área, utilizando referenciais das teorias decoloniais, em debate com o campo dos direitos humanos.

\section{Direitos humanos como caminho contra-hegemônico para a decolonização das produções em Ciências da Religião e Teologias}

A decolonização das CRT passa por uma revisão profunda de teorias e práticas epistêmicas que orientam a construção do saber e do fazer teológico pelo caminho da afirmação das diferenças e reconhecimento das assimetrias dentro e fora das religiões. E isso significa compreender o papel majoritário que os cristianismos ocupam nas Américas e como tal lugar exige uma postura humilde na linha da que Boaventura de Sousa Santos chama de interculturalidade como parte de uma hermenêutica diatópica (SANTOS, 1997). Essa postura exige que cada grupo ideológico, religioso, político, social revise criticamente os referenciais de sua própria cultura, reconhecendo lacunas, injustiças históricas das quais formou parte, para então abrir-se ao diálogo intercultural franco em uma nova forma de produção de conhecimento.

A hermenêutica diatópica exige uma produção de conhecimento coletiva, participativa, interativa, intersubjetiva e reticular. Deve ser prosseguida com a consciência de que existirão sempre áreas sombrias, zonas de incompreensão e ininteligibilidade irremediáveis, as quais, para evitar a paralisia ou faccionalismo, devem ser relativizadas em nome de interesses comuns na luta contra a injustiça social (SANTOS; SANTOS; MARTINS, 2019, p. 356).

O caminho dessas revisões também deve enfrentar uma contextualização honesta que prescinde da ideia de neutralidade, da associação de conhecimento com as perspectivas únicas da racionalidade e da verdade objetiva, e aposta em um conhecimento experiencial, conectado às vivências. Neste sentido, a 
ambiguidade do campo de estudos das religiões, que não encontra parcerias e reconhecimento pleno dentro nem fora do campo científico.

Essa revisão dentro do campo dos estudos das religiões é emblemática, na medida em que a área recebe olhares enviesados, sendo identificada com elementos de uma racionalidade pré-moderna, quando popularmente Teologia se mescla ao seu objeto de estudo, as religiões. Não se trata apenas de um equívoco de interpretação leiga, mas também de um sentimento que circunda a área que, em parte, está identificada com a premissa da divindade como uma realidade ontológica. Isso não significa, de modo algum, que as CRT devem afirmar sua neutralidade em relação ao seu objeto. Muito pelo contrário, a perspectiva decolonial nos impele a assumir outras lógicas epistêmicas como legítimas. Assim como as epistemologias de gênero afirmaram sua “objetividade situada e parcial” (HARAWAY, 1995), os estudos das religiões podem reivindicar sua sensibilidade metafísica dentro do campo científico, sensibilidade tal que considera as sutilezas e abstrações como formas legítimas de produção de conhecimento.

Ao reconhecer as religiões como parte da sociedade plural e democrática contemporânea e como legítimas nos espaços de produção do saber e de participação na esfera pública, mobiliza-se um esforço coletivo para revisar as fronteiras abissais estabelecidas artificialmente entre modernidade e tradição.

É importante observar que os direitos humanos estão diretamente ligados a essa discussão. Temas como pluralismo religioso e liberdade religiosa são propiciados a partir de uma lógica de Estados modernos e laicos, na qual também se originaram os princípios atuais de direitos humanos.

Boaventura de Sousa Santos (2014) indica que a concepção atual de direitos humanos - secular, universalista, estatal, ocidental e individualista (focada nos sujeitos) - entra em contraste com o que ele chama de "teologias políticas" (2014, p. 38) como "diferentes modos de conceber a intervenção da religião, como mensagem divina, na organização social e política da sociedade" (SANTOS, 2014, p. 38), já que as teologias políticas, que podem ser traduzidas como a dimensão pública das religiões ou religiões públicas (MONTERO, 2016), se constituem como antisseculares, muitas vezes hostis ou ambíguas em relação ao Estado, comunitárias, podendo ser ocidentais ou não (SANTOS, 2014).

Nesse sentido, há que se reconhecer as tensões envolvidas na aproximação dos campos de estudos das religiões e dos direitos humanos, 
no entanto, tal aproximação tem por base restabelecer caminhos para a decolonização das áreas de estudos das religiões.

Ao levarmos em conta tanto os debates sobre direitos humanos de forma intercultural, quanto a questão de que a religião é um marcador interseccional fundamental e constituinte da esfera pública, torna-se pertinente pensar como se dá a participação das religiões e das teologias políticas nas lutas contrahegemônicas. (...) Há que se compreender o quanto as religiões estiveram ao longo da história humana atreladas a processos de violência, exclusão, dor e subalternidades, evocando um quadro interpretativo dialético, para além do olhar simplificado que trata as religiões majoritárias como colonizadoras e opressoras e adentrando as ambiguidades enfrentadas na vivência cotidiana de fé e na defesa de uma identidade/pertença religiosa. (FRANCO, DIAS, 2021, p. 321).

O campo de estudos das religiões está conectado a essas tensões inerentes a seus objetos. Nesse sentido, as religiões e os estudos das religiões têm preocupações que perpassam fortemente o campo dos direitos humanos, como a noção de dignidade. Os direitos humanos nos levam ao questionamento sobre em quais humanos/as cabe a noção de dignidade. Judith Butler (2018; 2019) indica que a precariedade inerente à condição humana não é distribuída de maneira igual. Os pressupostos normativos que ditam "vidas vivíveis" estão ligados aos padrões e processos de humanização de certos sujeitos ou grupos e desumanização de outros. Tais padrões baseiam-se em princípios hegemônicos e coloniais. Dessa forma, a dignidade - que em princípio parece um direito da condição humana universal - acaba submetida a lógicas coloniais excludentes, em especial quando a humanidade é considerada como um conceito abstrato e não localizado a partir das realidades vividas.

Os estudos das religiões estão diretamente ligados a esse processo, na medida em que a universalização de uma noção de direitos humanos desconsidera as formas plurais de se estabelecer uma esfera secular (CASANOVA, 2007), levando à marginalidade os estudos das religiões e a categoria religião nos debates interseccionais (FRANCO; DIAS, 2021).

Boaventura de Sousa Santos (1997) entende que só é possível democratizar a noção de direitos humanos ao se adotar uma perspectiva multiculturalista que permite noções plurais não somente de direitos humanos, mas do próprio humano e de sua dignidade inerente. Isso reflete em perspectivas pluralistas dentro do universo religioso e teológico. Em "E 
se Deus fosse um ativista de Direitos Humanos", o autor (SANTOS, 2014) indica que as teologias pluralistas e progressistas (como as teologias feministas, queer, negra...) têm potência para realizar formas de lutas contrahegemônicas no campo de direitos humanos, porque utilizam a fé como instrumento de contestação das desigualdades e libertação das opressões.

Podemos apontar alguns exemplos que têm ocorrido na tarefa decolonial dos estudos das religiões, que se aproximam muitas vezes da concepção multicultural dos direitos humanos. Kwok Pui-Lan (2015) indica que os diálogos inter-fé para a promoção de uma cultura de paz global devem envolver o conceito de polidoxia, que permite a possibilidade de visões plurais sobre o divino, ou a perpectiva de que "os cristãos não têm monopólio da revelação de Deus, e que a divindade deveria ser compreendida em termos de multiplicidade, irrestringibilidade e relacionalidade" (PUI-LAN, 2015, p. 74). Embora a autora não tenha se referido ao campo epistemológico teológico diretamente e mais ao campo das inter-relações institucionais religiosas, podemos utilizar suas reflexões sobre polidoxia para compreender que as produções em Ciência(s) da(s) Religião(ões) e Teologia(s) precisam abrir-se a outras concepções teológicas que não as cristãs.

Outro esforço decolonial do campo de estudos das religiões tem sido realizado por Claudio Ribeiro (2020a; 2020b) que por meio da proposta do princípio pluralista, articula elementos das teorias decoloniais, como: o conceito de entre-lugares (BHABHA, 1998) e as possibilidades híbridas de construção identitária criativa e resistente em relação aos sistemas de poder; a desobediência epistêmica (MIGNOLO, 2010, WALSH, 2009) como forma de desestabilizar as centralidades do saber; com conceitos de outras matrizes teóricas como transdisciplinaridade e a complexidade (MORIN, 2010) como elementos necessários à construção de uma transreligiosidade; o conceito de polidoxia (PUI-LAN, 2015) para questionar as certezas, universalismos e estabilidades que perpassam relações autoritárias e objetificantes, trazendo a superação do binômio ortodoxia-polidoxia dentro do contexto do pluralismo religioso. E, finalmente, Claudio Ribeiro (2020) considera a diversidade antropológica, que assume uma "nova linguagem teológica, forjada nas expressões da corporeidade, da sexualidade e dos desejos humanos, associadas às dimensões místicas de formas de vida marcadas pela (...) afirmação da diferença” (RIBEIRO, 2020a, p. 225). Claudio Ribeiro tem sustentado um caminho de aproximações teóricas distintas, de forma a conduzir a um pluralismo como base da prática teológica, considerando perspectivas dos direitos humanos nos diálogos inter-fé. 
Já o teólogo Carlos Alberto Cunha (2018) propõe uma Teologia de Fronteira, apoiada na perspectiva de Mignolo (2003) de "gnose liminar". Walter Mignolo aponta para a emergência de novos lugares de enunciação, uma razão pós-ocidental que luta para afirmar saberes subalternizados. Esta outra forma de razão ou "outro pensamento" (MIGNOLO, 2003, p. 103), liminar, de fronteira, desloca o foco e o poder da enunciação do centro para as margens, para histórias locais, não oficiais, sem negar os conhecimentos construídos pelos sistemas ocidentais hegemônicos, mas restabelecendo outras bases de pensamento e de circulação do saber. "Nessa interseção uma dupla crítica torna-se um pensamento liminar, já que criticar a ambos implica em pensar a partir de ambas as tradições, e, ao mesmo tempo, de nenhuma delas" (MIGNOLO, 2003, p. 102). Este "aprender a desaprender" (MIGNOLO, 2003) típico dos espaços liminares é o caminho da decolonização do saber, trilhado por quem sente a diferença colonial (MIGNOLO, 2003) a partir da fronteira. Enrique Dussel (2016) chama tal processo de transmodernidade, que ultrapassa os limites epistêmicos estabelecidos no pensamento moderno, construindo novas formas de articulação do conhecimento.

Com base nesse pensamento, Cunha (2018) propõe uma Teologia de Fronteira, indicando as possibilidades de negociação, trocas e permeabilidades presentes nessa condição. A zona fronteiriça, lembra o autor, provoca mudanças, desestabiliza a ordem e "cede espaço ao complexo" (CUNHA, 2018 , p. 15). Sendo um lugar de contestação política, "a margem é o local onde uma nova consciência emerge da repressão acarretada pela missão civilizadora". Nesse sentido, a teologia de fronteira deve estar envolvida com o "desengajamento decolonial dos povos originários de diferentes regiões do mundo" (CUNHA, 2018, p. 16), "rearticulando suas antigas cosmologias, artes, ciências e saberes” (MIGNOLO; SOUZA, 2015, p. 395). A sensibilidade com as diferenças é um traço fundamental dessa decolonialidade.

A teologia de fronteira "abre espaço para uma razão subalterna lutando para afirmação dos saberes historicamente subalternizados. O desvinculamento epistêmico demanda um aprender a desaprender para aprender a partir da margem" (CUNHA, 2018, p. 18). "Toda mudança de decolonização política (não-racistas, não heterossexualmente patriarcal) deve suscitar uma desobediência política e epistêmica [...]. A desobediência civil sem desobediência epistêmica permanecerá presa em jogos controlados pela teoria política e pela economia política eurocêntricas" (MIGNOLO, 2008, p. 287). 
Uma teologia decolonizada envolve assumir uma geopolítica de alteridades negadas, restabelecendo, inclusive, o campo das espiritualidades subalternizadas. A "transmodernidade" de Dussel (2013), que pressupõe a pluriversalidade e o diálogo intercultural, aponta para alternativas que não encontram escuta em uma monocultura moderna. A transmodernidade pressupõe uma "trans-teologia", para além da cristandade latino-germânica, reabilitando o cristianismo messiânico originário. (DUSSEL, 2013, p. 29-30).

Cleusa Caldeira (2019) sugere que este resgate do messianismo originário se volta à "coisa mesma da fé cristã", que por sua vez "designa o perdão e o nascimento da identidade relacional” (CALDEIRA, 2019, p. 1002). Cleusa propõe que o caminho de reabilitação do messianismo originário seja uma nova ordem de existência e de intersubjetividade, com reconhecimento mútuo e com o fim da violência inter-relacional - sem esquecimento da colonialidade. Sua atenção se volta às profundas fraturas que o racismo e a escravidão impuseram.

A Teologia Negra tem sido um campo que tem mobilizado profundas transformações em relação às narrativas hegemônicas coloniais. Mesmo tendo se iniciado no Norte (EUA), nos anos recentes, a Teologia Negra latinoamericana traz importantes e indigestos cutucões como os apontados por Cleusa Caldeira que indicam "um compromisso com rostos concretos que vivem a opressão cultural e étnica" (CALDEIRA, 2019, p. 993).

Para Maldonado-Torres (2007, p. 145), a suspeita teológica acerca da humanidade dos/as indígenas e dos/as negros/as, foi crucial para desenvolver a colonialidade do ser e do saber, juntamente com o racismo e a exclusão ontológica (MALDONADO-TORRES, 2007, p. 145). Isso quer dizer que a participação do cristianismo nos processos coloniais foi profunda. Dessa forma, Cleusa Caldeira (2019, p. 999) afirma que "a decolonização do cristianismo aparece como um imperativo ético e epistêmico".

Outras ramificações teológicas contestadoras também têm apontado caminhos para a decolonialidade da área. É o caso da Teologia Indecente, de Marcella Althaus-Reid (2005), que relembra como Deus se travestiu de humano em Jesus e quão opressiva pode ser a "decência" da teologia tradicional.

Teologia indecente nada mais é do que aquela que questiona e desnuda as camadas míticas da opressão múltipla na América Latina, uma teologia que, tomando o ponto de partida na encruzilhada da Teologia da Libertação e do pensamento queer, refletirá sobre a opressão econômica e teológica com paixão e imprudência. Uma teologia indecente questionará o tradicional campo latino- 
americano da decência e a ordem que permeia e sustenta as múltiplas estruturas (eclesiológica, política e amorosa) da vida em meu país, Argentina, e em meu continente. (ALTHAUS-REID, 2005, p.12, tradução nossa)

Além desses exemplos, outras importantes revisões no campo epistemológico ligado às religiões têm ocorrido, como o reconhecimento de cosmologias indígenas associadas à agricultura familiar e modos de vida em várias esferas, que levaram à institucionalização do Bem-viver em países como Bolívia e Equador. Esse é um ponto certamente complexo e que envolve muitos desafios que não serão alvo deste texto. Mas vale ressaltar que legitimar lógicas contra-hegemônicas, que reconhecem a espiritualidade como parte desses saberes, é tarefa para uma decolonização da área de CRT.

\section{Considerações Finais: apontamentos para decolonialidade de Ciência(s) da(s) Religião(ões) e Teologias}

O que quisemos levantar com essas breves reflexões é que a noção multicultural dos direitos humanos - que reconhece as diferenças e olha para os grupos subalternizados como donos de saberes próprios, portadores de uma voz que precisa ser escutada e para as margens como lócus criativo de novas enunciações - pode subsidiar as transformações epistemológicas nas quais o campo de estudos das religiões precisa se engajar.

Para nossas considerações e reflexões finais, deixamos alguns tópicos, indicativos da longa caminhada que a(s) Ciência(s) da(s) Religião(ões) e Teologia(s) precisa(m) trilhar para a decolonização epistemológica de seu campo.

1. Revisar criticamente o fazer epistêmico das áreas de estudos das religiões, considerando lógicas estabelecidas a partir de vivências e saberes locais, como a teologia negra, teologia feminista, teologia queer, bem-viver, além de priorizar autoras/es locais, que fortaleçam as produções latinas da área;

2. Na seleção de doutorandas/os e mestrandas/os, dar espaço de forma prioritária - até que um equílibro maior entre os campos se estabeleça - a estudos de natureza crítica e contra-hegemônica em relação ao status quo da área;

3. Ampliar a contratação de mulheres, docentes LGBTQIA+, professoras/es negras/os, docentes com deficiência, de modo a formar um quadro docente representativo da pluralidade existente; 
4. Diversificar a contratação de estudiosas/os de campos e teorias contra-hegemônicas, ligados a estudos de tradições não cristãs;

5. Fortalecer intercâmbios das Ciência(s) da(s) religião(ões) e Teologia(s) com outros campos do saber;

6. Promover um trabalho de compreensão pública sobre as Ciência(s) da(s) Religião(ões) e Teologia(s). É preciso atuar para modificar o sentimento público de desconfiança em torno do campo dos estudos de religião;

7. Trabalhar na reconstrução de algumas categorias conceituais da área, à luz das vivências locais, como categorias que hoje estão sendo trabalhadas de modo universalizado e genérico, sem um enquadramento específico adequado, por exemplo: a categoria dos sem religião, que pode mundialmente abarcar uma multiplicidade de posicionamentos, desde pessoas indiferentes à religião, desvinculadas de uma institucionalização, até pessoas ateístas e agnósticas (FRANCO, 2021), carecendo de pesquisas geograficamente localizadas e com autoras/es que trabalhem a situação latina dos/as sem religião; a categoria dos/as evangélicos/as, que, quando abordada desse modo acaba por se aproximar de uma visão leiga, contribuindo pouco para o campo científico. Embora esse ponto não tenha sido especificamente tratado nesse texto, consideramos que ele faz parte de uma revisão epistemológica em Ciência(s) da(s) religião(ões) e Teologia(s);

8. Articular a produção acadêmica com atuações de cunho extensionista, considerando parcerias com entidades não governamentais e civis, como coletivos de gênero, negros, periféricos, formados por grupos religiosos minoritários;

9. Priorizar produção de conhecimento e referenciais locais em relação aos objetos de estudo;

10. Contribuir para a consolidação da área de estudos da religião da América Latina a partir de referências locais. 


\section{Referências}

AGUIRRE, Javier. Religiones, teologías y colonialidad: hacia la decolonización de los estudios académicos de las religiones y las teologías, Revista de Estudios Sociales. no. 77, 2021, pp. $76-92$

ALTHAUS-REID, Marcella. La teología indecente: perversiones teológicas en sexo, género y política. Barcelona: Bellaterra, 2005.

BHABHA, Homi K. O Local da Cultura. Belo Horizonte: UFMG, 1998.

BUTLER, Judith. Vida Precária: os poderes do luto e da violência. Belo Horizonte: Autêntica, 2019 [Kindle Edition].

CALDEIRA, Claudia. Teologia negra: a fenomenologia do damné como caminho de humanização. Horizonte, Belo Horizonte, v. 17, n. 53, p. 991-1020, maio/ago. 2019

CASANOVA, José. Reconsiderar la secularización: una perspectiva comparada mundial. Revista Académica de Relaciones Internacionales, n. 7, p. 1-20, 2007.

CUNHA, Ana Luiza Salgado. Direitos Humanos e Religiões. E se Deus fosse mesmo um ativista de Direitos Humanos? Perspectivas e Diálogos: Revista de História Social e Práticas de Ensino, v. 1, n. 5, p. 149-167, 2020.

CUNHA, Carlos Alberto Motta. Teologia decolonial e epistemologias do Sul Interações: Cultura e Comunidade, vol. 13, núm. 24, 2018.

CURIEL, Ochy. "Critica poscolonial desde las practicas politicas del feminismo antirracista". Nómadas. Bogatá, Colombia: Fundacion Universidad Central (26): 92-101, 2007.

. "Superando la interseccionalidad de categorías por la construcción de un proyecto político feminista radical. Reflexiones en torno a las estrategias políticas de las mujeres afrodescendientes". In: WADE, Peter; GIRALDO, Fernando Urrea; VIVEROS, Mara. Raza, etnicidad y sexualidades: ciudadanía y multiculturalismo en América Latina. Bogotá, Colombia: Universidad Nacional de Colombia, 2008.

DUGGAN, J. Dissonância epistemológica: descolonizando o "cânon" teológico pós-colonial. Concilium, Petrópolis, n. 350, p. 10-18, 2013.

DUSSEL, Enrique. Europa, modernidade e eurocentrismo. In: LANDER, Edgardo (org.). A colonialidade do saber: eurocentrismo e ciências sociais. Perspectivas latino-americanas. Buenos Aires: Clacso, 2005. p. 24-32.

1492, el encubrimiento del otro: hacia el origen del mito de la modernidade. La Paz: Plural Editores, 1994.

350, p. 19-30, 2013.

. Descolonização epistemológica da teologia. Concilium, Petrópolis, v.

Transmodernidade e interculturalidade: interpretação a partir da filosofia da libertação. Revista Sociedade e Estado, Brasília, n. 1, p. 51-73, jan./abril. 2016.

Política de la liberación. Vol.II, Madrid: Trotta, 2009 
ESCOBAR, Arturo. El lugar de la naturaleza y la naturaleza del lugar: ¿globalización o postdesarrollo? En Edgardo LANDER, La colonialidad del saber. Buenos Aires: CICCUS/ CLACSO, 2011

FRANCO, Clarissa De. "Um olhar contra-hegemônico e pluralista sobre o quadro religioso global desde as epistemologias do sul”. Em: RIBEIRO, Claudio de Oliveira. Diversidade religiosa e o princípio pluralista. São Paulo: Recriar, 2021, p. 11-46.

FRANCO, Clarissa De; DIAS, Tainah Biela. Religião, direitos humanos e interseccionalidades: reposicionando a categoria "religião" no debate interseccional. Revista Estudos de Religião. V. 35, n. 2, maio-ago, 2021.

HARAWAY, Donna. Saberes Localizados: a questão da ciência para o feminino eo privilégio da perspectiva parcial. Cadernos Pagu, 5, 7-41, 1995.

HARDING, Sandra. Is Science Multicultural? Postcolonialisms, Feminisms, and Epistemologies. Bloomington: Indiana University Press, 1998.

KURU, Ahmet. Secularism and State Policies Toward Religions: The United States, France, and Turkey. Cambridge: Cambridge University Press, 2009.

KUZMA, Cesar; ANDRADE, Paulo Fernando Carneiro de (org.). Decolonialidade e práticas emancipatórias: novas perspectivas para a área de Ciências da Religião e Teologia. São Paulo: Paulinas, 2019.

LANDER, Edgardo (org). A colonialidade do saber: eurocentrismo e ciĺncias sociais. Perspectivas latinoamericanas. Colección Sur Sur, CLACSO, Ciudad Autónoma de Buenos Aires, Argentina, 2005.

LUGONES, María. Peregrinajes. Teorizar una coalición contra múltiples opresiones. Buenos Aires: Ediciones Del Signo, 2021

LOPES, Antonio Lisboa Lustosa. Chaves descoloniais: para uma leitura da prática pastoral. São Paulo: Saber Criativo, 2021.

MALDONADO-TORRES, N. Sobre la colonialidad del ser: contribuiciones al desarrollo de un conpecto. In: CASTRO-GÓMEZ, S; GROSFOGUEL, R (org.). E1 giro decolonial: reflexones para una diversidad epistémica más allá del capitalismo global. Bogotá: Siglo del Hombre Editores; Universidad Central, Instituto de Estudios Sociales Contemporáneos y Pontifícia Universidad Javeriana, Instituto Pensar, 2007. p.127-167.

MIGNOLO, Walter. Histórias locais/Projetos globais: colonialidade, saberes subalternos e pensamento liminar. Belo Horizonte: Ed. UFMG, 2003.

Os esplendores e as misérias da "ciência": colonialidade, geopolítica do conhecimento e pluri-versalidade epistémica. In: SANTOS, Boaventura de Sousa (org.). Conhecimento prudente para uma vida decente: um discurso sobre as ciências revisitado. São Paulo: Cortez, 2004. p. 667-707.

A colonialidade de cabo a rabo: o hemisfério ocidental no horizonte conceitual da modernidade. In: LANDER, Edgardo (org.). A colonialidade do saber: eurocentrismo e ciências sociais. Perspectivas latino- -americanas. Buenos Aires: Clacso, 2005. p. 33-49. 
. La descolonización del ser y del saber. In: MIGNOLO, Walter; SCHIWY, Freya; MALDONADO-TORRES, Nelson (orgs.). Des-colonialidad del ser y del saber: (videos indígenas y los límites coloniales de la izquierda) en Bolivia. Buenos Aires: Del Signo, 2006. p. 25-30.

Desobediência epistêmica: a opção descolonial e o significado de identidade em política. Cadernos de Letras da UFF - Dossiê: literatura, língua e identidade, no 34, 2008.

Desobediencia epistémica: Retórica de la modernidad, lógica de la colonialidad y gramática de la descolonialidad. Buenos Aires: Del Signo, 2010.

La idea de América Latina. Barcelona, Gedisa, 2005

MONTERO, Paula. "Religiões Públicas" ou religiões na Esfera Pública? Para uma crítica ao conceito de campo religioso de Pierre Bourdieu. Relig. Soc. 36 (1), Jun 2016.

PANOTTO, Nicolás. Religião, Política e Pós-Colonidade na América Latina. São Paulo: Recriar, 2020.

Descolonizar o saber teológico na América Latina: Religião, educação e teologia em chaves pós-coloniais. São Paulo: Recriar, 2019.

PROVINCIATTO, Luis Gabriel. Decolonialidade e práticas emancipatórias: novas perspectivas para a área de Ciências da Religião e Teologia (Resenha). Paralellus, Recife, v. 10, n. 24, mai./ ago. 2019, p. 339-345

PUI-LAN, Kwok. Globalização, gênero e construção da paz. São Paulo: Paulus, 2015.

QUIJANO, Anibal. Colonialidad del poder y clasificación social. En Journal of WorldSystems Research, New York, pp.342-386

QUIJANO, Anibal. Colonialidade do poder, eurocentrismo e América latina. Em: LANDER, Edgardo (org.). A Colonialidade do saber, eurocentrismo e Ciências sociais. Buenos Aires: CLACSO, 2005.

RIBEIRO, Claudio de Oliveira. Religião, decolonialidade e o princípio pluralista. Numen, Revista de Estudos e Pesquisa da Religião, v. 23, no. 1, 2020a.

RIBEIRO, Claudio de Oliveira. Princípio Pluralista. In: RIBEIRO, Claudio de Oliveira; ARAGÃO, Gilbraz; PANASIEWICZ, Roberlei (orgs.). Dicionário do Pluralismo Religioso. São Paulo: Editora Recriar, 2020b.

SAID, Edward. Orientalismo. Barcelona: Debate, 2002

SANTOS, Boaventura de Sousa. Para além do Pensamento Abissal: das linhas globais a uma ecologia de saberes. Revista Crítica de Ciências Sociais, v. 78, n. 1, p. 71-94, 2007.

. Uma concepção multicultural de direitos humanos. Lua Nova, n. 39, p. 105-124, 1997.

. Se Deus fosse um ativista dos direitos humanos. São Paulo: Cortez, 2014.

. Reconhecer para libertar: os caminhos do cosmopolitismo multicultural. Rio de Janeiro: Civilização Brasileira, 2003. 
SANTOS, Boaventura de Sousa; SANTOS, Cecília MacDowell; MARTINS, Bruno Sena (Orgs.). Quem Precisa dos Direitos Humanos? Precaridade, Diferenças, Interculturalidade. Coimbra: Almedina, 2019.

SANTOS, Boaventura de Sousa; MENESES, Maria Paula (orgs.). Epistemologias do Sul. Coimbra: Almedina, 2009.

SENRA, Flávio; SAMPAIO, Dilaine; RIBEIRO, Claudio. Documento de área. Área 44: Ciências da Religião e Teologia. Ministério da Educação (MEC), Coordenação de Aperfeiçoamento de Pessoal de Nível Superior (CAPES), Diretoria de Avaliação (DAV), 2019.

TODOROV, Tzvetan, La conquista de América. E1 problema del otro. Buenos Aires: Siglo XXI, 2003.

USARSKI, Frank. História da Ciência da Religião. Em: PASSOS, J. D. \& USARSKI, F. (org.). Compêndio de Ciência da Religião, Parte I. São Paulo: Paulinas/Paulus, 2013.

WALSH, Catherine. La Educación Intercultural en la Educación. Peru: Ministerio de Educación. (documento de trabalho), 2001.

Interculturalidad Crítica/Pedagogia decolonial: apuestas (des)de el in-surgir, reexistir y re-vivir. In: Memórias del Seminário Internacional "Diversidad, Interculturalidad y Construcción de Ciudad”, Bogotá: Universidad Pedagógica Nacional 17-19 de abril de 2007.

WALSH, Catherine. Interculturalidad, Estado, Sociedad: Luchas (de)coloniales de nuestra época. Quito: Universidad Andina Simón Bolívar/Abya Yala, 2009.

YOUNTAE, An; CRAIG, Eleonor (eds.). Beyond man, race, coloniality and philosophy of religion. NY: Duke university Press, 2021.

Submetido em: 27-10-2021

Aceito em: 27-1-2022 